\title{
The Practice of Scaling Down Practical Assessment Components of Agriculture in Junior Secondary Schools Curriculum: A Synthesis of Teachers Perceptions
}

\author{
Keba Hulela \\ Correspondence: Keba Hulela, Senior Lecturer, Agricultural Education Department of Agricultural Economics, \\ Education and Extension Botswana College of Agriculture Private Bag 0027, Gaborone, Botswana.
}

Received: June 5, 2015

doi:10.11114/jets.v5i3.2197
Accepted: January 10, $2017 \quad$ Online Published: February 5, 2017

URL: http://dx.doi.org/10.11114/jets.v5i3.2197

\begin{abstract}
This ethnographic research study aimed at investigating factors that contributed to the decline in the number of practical assessed projects in junior secondary agricultural education assessment in Botswana. Participant-observation technique was used to gather data in the form of field notes from in-service teachers at BCA and in-school teachers during school visits teaching practice and lessons at BCA respectively. Students' performance assessment in practical agriculture measures the extent to which students performed their tasks. The study used two groups of teachers; five (5) in-service student teachers pursuing their Bachelor of Science (BSc) degree in Agricultural Education at Botswana College of Agriculture and five (5) in-school teachers of agriculture to investigate the decline in the number of practical projects assessed in schools. The participants were purposely selected for their proximity to the researcher. Field notes prepared during school visits through interviews and surveys using open ended question were used to gather data for this study. Narrative data were gathered and analysed by coding the emerging themes and applying descriptive analysis. The study took on theoretical issues forming the basis for the understanding of the culture of teaching and assessing practical agriculture projects to include (1) teacher motivation (2) validity issues on assessment (3) teaching standards, teacher education, and (4) practices in teaching, and students' attitudes. The study concluded by discussing implications on education of agriculture science teachers.
\end{abstract}

Keywords: assessment, scaling down, projects, teacher participants, agricultural education, performance assessment, practical agriculture

\section{Introduction}

Agriculture is taught in secondary schools in Botswana as a practical subject. The practice has existed in schools since the subject was introduced into the curriculum in the mid-1970s with both theory and practical components. This ethnographic research study aimed at investigating factors that contribute to the decline in the number of practical assessed projects in junior secondary agricultural education assessment.

According to Retallick (2010p 59) agricultural education is a unique subject for schools as it demands the infusion of classroom theories into the real world through "the application of the concepts and principles learned in the agricultural education classroom in planned, real-life settings under the supervision of the agriculture teacher." Gant et al. (2012) alluded to the fact that a comprehensive agricultural education program was imperative in schools or universities to prepare learners to develop some cognitive, affective and psychomotor skills. Knobloch, Ball and Allen (2007) advised that agriculture in schools curriculum has provided stuntedness, connectedness, and authenticity in education. Similarly, as stated in Hulela and Miller (2003) the curricular that infuses agriculture is beneficial in education because it balances learning, helping students plan their jobs and developing entrepreneur skills. This culture has prevailed in several education systems where practical and technical subjects have been part of the curriculum. In this ethnographic study the aim was to explore the context in which agriculture is taught in schools, processes that are in place to assess agricultural components and make meaning out of the context based on field notes gathered through interviews and interactions with selected schools in Botswana.

Generally, the agriculture industry forms part of the economic foundation of many countries (Alam et al., 2009; Egun 2009), particularly in the developing world. The authors further indicated that agriculture provides opportunities for employment creation and human resource mobilisation hence an important component of schools curriculum. The 
teaching of agriculture in schools has always consisted of “... written examination(s), student project(s) and student demonstration(s) of technical skills to measure proficiency in a specific technical field through the application of national standards in such technical field" (Talbert, Vaughn, Croom, \& Lee, 2007, p. 418 as quoted in Retallick 2010, p 59) (Camp et al., 2009 p...). This is the practice of teaching practical subjects, but not as a science in schools. Agriculture is not considered as a science in Botswana schools, but as a practical subject that is assessed to appreciate the performance of students. With regard to practicality of the subject it may not be clear as to how much of these practical areas are assessed.

\section{Practical Agriculture in Schools}

Practical agriculture has been part of the assessment since the subject was introduced into the curriculum in Botswana in the mid-1970's (Hulela and Miller, 2003). As noted, instruction of such a subject involved hands-on, field trips, simulations, writing activities and role-play to enable students apply the knowledge and skills acquired through classroom learning (Cimer, 2006). In this manner, agriculture helps to develop the psychomotor skills of students and this has been well documented (Osborne, 1983). Such a component creates the balance of knowledge and practical skills taught at tertiary level, but still a large number of farmers lack experience of agricultural production. According to Masole (2011) the conduct of practical agriculture examinations in Botswana secondary schools was faced with the predicament of lack of standards, inadequate qualified teachers, inadequate resources, poor administrative support, time and financial constraints as well as performance standards. Although resources have improved in schools little research has been conducted to investigate further on practical assessment.

Assessment of students in agricultural education is vital (Cano, 2005). For Botswana's junior secondary schools, the assessment is made up of three components. This include, paper 1 which comprises of forty (40) multiple choice items anchored with four key alternatives to allow students or learners choose the answer rather than making their own responses (An objective test does not cater for student's own responses). Then paper two forms the second part of the assessment made up of semi- structured items, completion and short essay type of questions requiring the learners to write their own responses or extended brief answers. The third component is not a pen and a pencil-paper, but rather made up of a collation of a variety of practical agriculture pieces of work conducted by students. This is the continuous assessment [CA] which according to Chan (2004) can be characterised by a variety of attributes, conducted and measured over a long period.

The assessment comprises of scores gathered from hands-on and inquiry agriculture projects. These are students' projects as indicated by Talbert, Vaughn, Croom, \& Lee (2007) to prepare students technically. Each practical component conducted by students has a role to play in the final assessment scores. Important to note here is the third component of the assessment that is school-based on practical instruction on production skills on goats / sheep, fish or rabbits, bees or pigs, chicken production (broilers or layers), vegetables, fruit trees, and field crops. Such a culture of conducting practical activities is practiced in schools under the supervision of agriculture teachers as a curriculum requirement. The expectations are that at the end of such activities out in schools students would be assessed on all projects. Therefore, the scaling down of a number of projects from six (6) to one (1) has introduced a new culture of assessing one component of practical agriculture activities in the in schools.

According to Heyneman and Fremer (2008) standardised assessment serves as an important quality assurance function on students' performance in classroom instruction followed by curricular content. It is one of the three factors teachers should consider in planning and delivering their classroom instruction. Assessment conducted by teachers in schools serves to diagnose students' problems, academic learning and progress, provides feedback and incentives, places students in the next level of education, plans instruction and establishes classroom equilibrium. Thus, a "good examination design can lead to social cohesion, it can help choose talent fairly, it can engender trust in public institutions, and it can give confidence in the general conduct of the public school system" (Heynemen,2009 p.11). Therefore, unprofessional conduct associated with procedures found in examinations tend to lower the integrity of a national assessment (Bulus and Rimfat, n.d). For example, student cheating during examinations, examination leakages, and bringing illicit materials into the examination rooms. These, compromise the quality of any country's examination and plunges them into disrepute.

Heyneman (2009) also stated that examinations have been used for a long time as a tool for selecting quality leaders based on their personal potential for achievement rather than through ascriptive criteria that is likely to create biasness on the basis of the characteristics such as race, gender or social status or inheritance, military power or political weight. The role of a teacher in examinations is therefore important (Bulus and Rinfat, n.d) to ensure examinations serve their function. Teachers therefore "should carry out continuous assessment regularly and the scores used adequately in the overall assessment of the child." Hare and Waterston (2003) found that students' assessment is a core activity of teaching and learning in schools. 


\subsection{Performance in Agriculture}

Measuring the performance of students in agriculture is one of the key responsibilities in quantifying the efficiency and effectiveness of the education system (Shahril 2011). For example, Syakima and Sapri and Shahril (2011), stated that to achieve the best performance in education it is important to measure performance of facilities in use. Dornody (1993 p63) has placed emphasis on the incorporation of science into agriculture for secondary schools paying a positive attention to students' "attitudes and performance, agriculture teacher attitudes and adoption" (p63) as well as resource sharing with science programs. Among other conclusions drawn from the same study were that teachers of agriculture should work closely with science departments developing, implementing, and evaluating agriculture science programs. This can also be interpreted to imply that competence development in the course of agricultural science should link to those acquired through science inquiry methods. Thus, demanding that, the teaching of agriculture should take into consideration investigatory and laboratory skills used in sciences. Evidence of what students do in the classroom is therefore crucial in education as it adds value to what a student becomes when graduating from a program. Examinations remained a crucial component of the education since they are used as a fair tool for students' evaluation (Heyneman and Fremer, 2008). This background shows that examinations require proper planning to ensure higher standards of education (Ibara 2008).

\subsection{Methodology and Materials}

The ethnographic study was set to understand the culture of practical assessment in agriculture and factors contributing to the scaling down of its components. In Botswana schools the study takes into cognisance the importance of students' performance in practical agriculture assessment, the culture of assessment, history background of assessment and its value. Participant-observation technique was found appropriate to gather qualitative data in the form of field notes from a total of ten participants purposively selected. According to Reeves, Kuper and Hodges (2008) such an approach to research created social interactions, behaviours, and perceptions that occur between the researcher and the groups involved.

The ten purposively selected participants in this study were teachers of agriculture who have had the opportunity to teach and assess agriculture practical projects as internal examiners in schools. Five of the participants were in-school teachers (currently teaching the subject in secondary schools). The other five were in-service teachers (currently at BCA pursuing their Bachelor of Science degree in Agricultural Education after they had taught the subject in schools with a Diploma qualification).The researcher observed agriculture practical projects in schools and learnt that only one project was being considered in the final examinations scaling down the practical components from eight to one in junior schools. The in-service participants were also purposively selected to participate in the study because they had experience of $\geq 5$ years in teaching before returning to BCA for their Bachelor of Science (BSc) degree in Agric Education. At the time of the study the participants took courses AEE 425: Management of Agricultural Enterprises in Schools and AEE 315: Curriculum Design and Development taught by the researcher where they discussed assessment and curricula issues. The participants showed willingness to share the information on the practice of practical assessment in schools. As indicated by Genzuk (n.d) the type of research combined analysis of practical document, interviewing of respondents and informants, direct participation and observation and introspection.

The study used four open ended questions requiring the informants to state their background in teaching, identify factors thought to contribute to the scaling down of the practical components from eight to one practical project to identify practical components of agriculture, and to outline challenges associated with the teaching of agriculture in schools.

\subsection{Research Question}

The question that the research aimed at answering was; what factors have contributed to the decline in the number of practical assessed agriculture science projects for the junior secondary agricultural education in Botswana?

\subsection{Selection of Participants}

The study involved the whole set up of agriculture departments in selected schools to understand their culture of teaching agriculture; their opinions and feelings as teachers of agriculture when only one component is assessed. The fact that practical agriculture component contributes equally well to the performance of students was important to education.

\subsection{In-service Agriculture Science Teachers}

The five (5) in-service teachers' perceptions of why the scaled down number of agriculture science practical projects in junior secondary schools could have changed since they joined the college for their upgrading. The group could provide relevant information as experienced and still involved in marking the agriculture science examinations during their college vacation. 


\subsection{In-school Agriculture Teachers}

The five n-school teacher participants currently teaching the subject were interviewed at their respective schools. Their perceptions were relevant in shedding light on understanding the culture of teaching and assessment of the subject of agriculture in schools. The researcher prepared field notes during interaction with participants in their secondary schools. The field notes were prepared following discussions on practical activities currently conducted by schools for examinations. The researcher's first hand experiences and previous involvement in Agricultural Education as an examiner and evaluator of the program activities were also used to inform the study.

\subsection{The Research Participant}

Ethnography is a type of social science research that investigates the practices and life of a group involved by the researcher becoming one of the participants. The research participant got immersed into the environment of the phenomenon to understand the culture of examining students in one practical agriculture component. Harris and Johnson (2000) defined ethnographic studies to mean a description which is written about the culture of an environment where data is gathered through direct observation, field notes and or content analysis. The researcher interrogated the participants to give their views, opinions and perceptions regarding the adoption of a single practical project when there were several practical projects conducted in schools.

\subsection{Trustworthiness of the Research}

According to Shenton (2004) credibility as viewed in this study is one of the principles to ensure the trustworthy of the study. The researcher in this study used several techniques such as field notes, survey questions and direct observations. The questions used to gather information were also assessed by colleagues in the department to check validity to gather information. The rationale for adopting the triangulation design as stated by Creswell (2002) was to strengthen the techniques for data collection in the study. For example, data used was obtained through interviews of in-service and in-school teachers using interview guided with four open ended questions. The questions used gathered realistic data to give credibility to measuring the phenomenon being studied. Data were also collected through the use of field notes collected during schools visits through discussions and observations of the school set ups. The findings of the study could be generalised to the ten (10) teachers of agriculture who participated in the interviews, interactions and would be reliable. Thus, as indicated by Shenton (2004) issues of internal validity, external validity, reliability and objectivity of the qualitative research were important in such a qualitative research.

\subsection{Content Analysis}

According to Hsieh and Shannon (2005) content analysis method as a technique in qualitative research has become widely used involving conventional, directed, and the summative content analysis. In this study the summative content analysis by Hsieh and Shannon (2005) in conjunction with the Thematic Content Analysis (TCA) described by Anderson (1997) were adopted for analysis. The summative content analysis which involved counting of key concepts or content, followed by the interpretation of the underlying context was used. The thematic content analysis involved steps outlined by Anderson (1997) which involved identifying the themes which emerged from interview transcripts or narrative statements gathered from participants during interviews. The TCA techniques were used in each of the questions to analyse data.

Question 1: On personal information: to analyse personal information of participants, table 1 was prepared to categorically insert respondents' information starting with the teacher's hypothetical name [pseudo- name] for anonymity, assigned codes, followed by the participants' gender, and experience in the field. The experiment included the number of years the participant has been in teaching, highest education attained, and whether or not have marked practical agriculture component at school (internal) and or served as external examiner.

Question 2: Identification of practical components: to determine the practical components offered and conducted by students with the help of teachers, the participants were asked to identify the levels at which the students were taught [forms $1-3$ ], practical components conducted at each level, to give short descriptions of what student carry out during class, state the skill [s] learnt, assessment method used and possible marks awarded for each area. The goal was to understand the culture of teaching and assessing the practical components in schools. The participants were also asked to rate the level of adequacy of assessment tools used to assess six (6) practical components [Field crops, Rabbit/Pig, Sheep or Goats, Fish/ Bees, Chicken: layers/broilers and Vegetable production] in schools to indicate, 1= adequate; $2=$ not adequate.

Question 3: Factors contributing to scaling down of practical components: To answer the objective on teacher participants' perceptions regarding the scaled down of projects in schools some narrative statements were gathered expressing the views, opinions and perceptions of teachers regarding the phenomenon of scaled down practical. The analysis of these qualitative data involved obtaining interview transcripts, highlighting relevant descriptions to the 
question, marking points, and categorising the data manually, coding 1 to 6 themes, identifying the themes, patterns and situations as guided by Glesne (1998) and Merriam (2009). Data gathered from the in-service group of respondents was analysed using content analysis. The process involved categorising information gathered into common concepts, theories, and themes and making meaning out of it.

Recruitment of participants in this study was purposive, selecting only those who were in-service students at BCA in a class of AEB 221 in 2013 and those in-school teachers visited by the researcher. The study used only those who were willing to participate. An informal explanation was made by the researcher to participants during AEB 221 lesson at $\mathrm{BCA}$ and to in-school participants on the importance of understanding the culture of teaching and assessment of agriculture in schools. As indicated by the Family Health International (n.d) an explanation was made to ensure teacher participants understood what it meant to participate in any research study so they can decide in a conscious and deliberate way whether to take part or not to participate (p 9).

\section{Results and Discussions}

Table 1. Respondents' personal characteristics and background in in teaching

\begin{tabular}{|c|c|c|c|}
\hline Teacher & Type & Gender & Background and experience \\
\hline $\begin{array}{l}\text { Teacher \# 1: John } \\
\text { - } \quad \text { Assist teacher, senior school }\end{array}$ & In-service & Male & 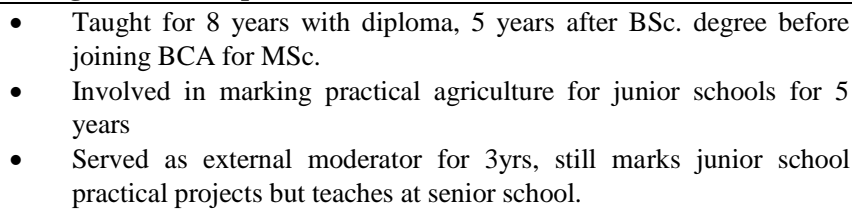 \\
\hline $\begin{array}{l}\text { Teacher \# 2: Judith } \\
\text { - } \quad \text { Assistant teacher }\end{array}$ & In-school & Female & $\begin{array}{l}\text { - Taught for } 8 \text { years, Holds B. Ed Agriculture with a component of } \\
\text { animal science, currently pursuing MSc Agric Education, BCA } \\
\text { Involved in marking practical agriculture since she resumed duty, } \\
\text { served as external moderation for } 1 \text { year }\end{array}$ \\
\hline $\begin{array}{l}\text { Teacher \# 3: Jacob } \\
\text { - } \quad \text { Assistant teacher }\end{array}$ & In-service & Male & $\begin{array}{l}\text { - Taught for } 8 \text { years after Diploma in Agric Education, involved in } \\
\text { marking internal practical projects, no external moderation } \\
\text { experience. } \\
\text { - Currently pursuing BSc. Agric Education degree }\end{array}$ \\
\hline $\begin{array}{l}\text { Teacher \# 4: Wanani } \\
\text { - } \quad \text { Assistant teacher }\end{array}$ & In- service & Female & $\begin{array}{l}\text { - Taught for } 7 \text { years, marked Agric projects in school. no external } \\
\text { moderator experience. } \\
\text { - Now pursuing BSc Agric education. }\end{array}$ \\
\hline $\begin{array}{l}\text { Teacher \# 5: Adani } \\
\text { - } \quad \text { Assistant teacher }\end{array}$ & In-service & Male & $\begin{array}{l}\text { - } 8 \text { years teaching with Diploma in Agric Educ, involved in marking } \\
\text { practical projects, currently pursuing BSc. Agric Education degree. } \\
\text { No experience on external moderation }\end{array}$ \\
\hline $\begin{array}{l}\text { Teacher \# 6: Jane } \\
\text { - } \quad \text { Assistant teacher }\end{array}$ & In-service & Female & $\begin{array}{l}\text { - Taught for } 9 \text { years, holds a Diploma in Agric education, marks } \\
\text { agriculture projects in her school, not involved in external } \\
\text { moderation. }\end{array}$ \\
\hline $\begin{array}{l}\text { Teacher \#7: Punie } \\
\text { - } \quad \text { Assistant teacher }\end{array}$ & In-school & Female & $\begin{array}{l}\text { Taught for } 10 \text { years, } \\
\text { Involved in, marking schools projects and served as external project } \\
\text { examiner, diploma in secondary education }\end{array}$ \\
\hline $\begin{array}{l}\text { Teacher \# 8: Metha } \\
\text { Senior Teacher Grade } 2\end{array}$ & In-school & Male & $\begin{array}{l}\text { - Taught for } 11 \text { years } \\
\text { - Currently marks projects in schools, and also serves as external } \\
\text { examiner. } \\
\text { - Holds a diploma secondary education }\end{array}$ \\
\hline $\begin{array}{l}\text { Teacher \# 9: Alec } \\
\text { Assistant teacher }\end{array}$ & In-school & Male & $\begin{array}{l}\text { - Taught } 9 \text { years before going for Bachelor of Science degree in Agric } \\
\text { Education. } \\
\text { Holds a BSC Agric Education, teaches, marks and serves as external } \\
\text { examiner }\end{array}$ \\
\hline $\begin{array}{l}\text { Teacher \# 10: Nancy } \\
\text { Senior Teacher grade } 2\end{array}$ & In-school & Female & $\begin{array}{l}\text { - Taught agriculture with a Diploma in Secondary Education for } 12 \\
\text { years, } \\
\text { - Participates in marking practical projects, never been invited to serve } \\
\text { as external marker }\end{array}$ \\
\hline
\end{tabular}

The following questions were answered in this study to understand the culture of teaching and assessment of practical components of agriculture in schools;

Question 1: What was your background [in teaching, marking and grading of practical agriculture] prior to joining the Botswana College of Agriculture for your Bachelor of Agric Science degree? Or the school where you are teaching?

Table 1 shows the background of participants in teaching, marking /grading of agriculture practical and their experience synthesised from data gathered. The first column contains hypothetical names of teachers interviewed, positions achieved in terms of teaching position held at work. The majority were assistant teachers while only one participant was a senior teacher. This means that the majority of the participants had not experienced any promotion since they joined teaching. The second column shows the category of teachers interviewed, while the third and fourth columns present the 
gender of participants and backgrounds information respectively. The overall teaching experience of informants in the study was relatively adequate ranging from $7-12$ years of teaching. The experiences presented in column four (Table 1) showed that majority of the participants had more than five years in teaching and were experienced with assessment procedures within their schools and as external examiners. At least the majority (90\%) of the informants started teaching with diploma qualifications while only $10 \%$ of the participants started with a Bachelor's degree in Education with the stream of Animal Science. Results also show that the majority of the in-school participants had a Diploma and were more experienced in terms of the number of years in the field.

Question 2: Which practical components of agriculture were considered for the final examinations when you joined teaching?

The participants were asked to name the practical agriculture projects which were conducted in junior secondary schools in the formal examinations. Participants were also asked to state practical projects offered in schools and indicate how they were assessed. The participants identified the projects as shown in Table 2 (column 2) and approach for assessment. Participants further indicated possible marks (column 5) allocated for each project and the skills (column 4) intended to be assessed. The total marks allocated for the five projects add up to 300 as shown in Table 2. This mark is scaled to $20 \%$ of the final examination for agriculture (Masole, 2011). The following challenges were raised by participants with regard the practice in handling practical activities which include ratio of students to practical activities in schools, skills identified for practical, ratio of students to teachers and resource inadequacy. For example, one respondent stated that "when raising chickens, the appropriate activities will include feeding, cleaning, drug administration, slaughtering, packaging and marketing. The students did not do or know all these and the school was ill-equipped thus students not adequately prepared or trained".

The participant further stated that 'Despite the few activities listed, too many students were expected to perform one activity in groups or teams. The skills and activities to be performed were not adequate for all students found in a school'

Teacher participants in this study implied that there were few projects in schools. For example, schools were limited to keeping a very small number of animals like; " two (2) goats, five (5) rabbits, one (1) batch of not more than 100 broiler chickens, one (1) bee keeping project and one (1) fish pond". These as pointed out by informants as not enough to impart enough skills and knowledge to secondary school kids for future use. Majority of the participants indicated that vegetable production had clear format of what skills students were expected to learn to do or perform while other projects do not have adequate guides. Out of the six areas presented to participants 5 were rated as 'inadequate' in terms of tools used for assessment. The respondents further expressed the concern that guidelines for optional practical components were inadequate thus making it a challenge to measure students' performance.

Table 2. Practical activities conducted in junior secondary schools

\begin{tabular}{|c|c|c|c|c|c|}
\hline & Practical project & Description & Skills assessed & Assessment Tool & Marks \\
\hline Form 1 & Field crops & $\begin{array}{l}\text { Land preparation, planting, } \\
\text { management and harvesting of the } \\
\text { crop }\end{array}$ & $\begin{array}{l}\text { Teachers select any } 5 \text { skills of } \\
\text { their choice to assess }\end{array}$ & inadequate & 50 points \\
\hline \multirow{2}{*}{ Form 2} & Sheep or Goats & $\begin{array}{l}\text { Feeding, management marketing, } \\
\text { milking }\end{array}$ & $\begin{array}{l}\text { Teachers select any } 5 \text { skills of } \\
\text { their choice to assess }\end{array}$ & inadequate & 50 points \\
\hline & Fish/ Bees & $\begin{array}{l}\text { Feeding, management marketing, } \\
\text { harvesting }\end{array}$ & $\begin{array}{l}\text { Teachers select any } 5 \text { skills of } \\
\text { their choice to assess }\end{array}$ & inadequate & 50 points \\
\hline Form 3 & $\begin{array}{l}\text { Vegetable } \\
\text { production }\end{array}$ & $\begin{array}{l}\text { Land preparation, planting, } \\
\text { management and harvesting of the } \\
\text { crop, plot stand, population, } \\
\text { cultivation }\end{array}$ & $\begin{array}{l}\text { Teachers select any } 5 \text { skills of } \\
\text { their choice to assess }\end{array}$ & adequate & 50 points \\
\hline Total & & & & & 300 points \\
\hline
\end{tabular}

Based on the information gathered (Table 2), teachers of agriculture in junior secondary schools in Botswana were given the mandate to identify specific skills to be learnt by students. These results imply that students in different schools were likely to be assessed on different skills and were also likely to show variations in the mark allocations, skills assessed and proficiency acquired by students. The student performance assessment from one school to the other was likely to vary depending on what project shall be available. The results also confirm that standards in education were important as they would provide guidance on the outcomes of any expected learning outcomes.

Teacher participants stated that resources were inadequate for agricultural projects thus contributing to limitations to appropriate job on students' assessment. Informants believed that conducting practical projects was an additional 
function to their classroom teaching. These negative perceptions about practical projects and extra mural activities in schools have been noted and have implications on the roles and functions of a teacher. Perhaps it was time higher education programs at Botswana College of Agriculture (BCA) set teaching and performance standards to guide preparations of agriculture teachers. Similarly, it was time for the Ministry of Education and Skills Development (MoESD) to consider teacher certification and licensing for selection of teachers into schools.

Question 3: What factors do you think contributed to the scaling down of the practical components from six to one in the schools' agriculture performance assessment?

Agriculture teacher informants were asked to describe the possible contributory factors leading to the scaling down of the practical components of the agriculture assessment from six to one project. The following thematic areas emerged from narrations made by informants;

Policy issues: The majority of informants indicated that the decision to scale down the project from six to one was a policy issue "directive" from the Botswana Examination Council (BEC)". They felt that although teachers "were not consulted" and should not be "bothered" after all the practical component of the subject was "demanding". The majority of the informants indicated that "we were not adequately paid for the projects" hence they were not concerned when the practical projects were suspended since they would not be under pressure from work.

As indicated by Ibukun and Oyewole (2011) authority responsible for examinations takes the lead in protecting its name and integrity as the organisation responsible for examinations. Malpractices in education cab in any form and may hamper the education system (Oche, 2012). The University of Cambridge Local Examination Syndicate (UCLES) for example, has run the examinations for many countries ensuring the standards were kept at a level where examinations will serve its purpose it was designed to serve. Similarly, it was not shocking as stated by the participants that the Botswana Examinations Council (BEC) saw a need to suspend some practical components of agriculture because of lack of standards guiding the school-based practical assessment as a whole and a reliability of scores given to students for practical".

Examination malpractices: one of the informants boldly stated that;

"For a long time the agriculture practical marks in secondary schools have been "cooked" but following the 2010 national strike, the situation became worse. In 2010, when the national go-slow strike started, some schools had not started their agriculture projects like growing crops, and livestock keeping were not managed. In the end, they submitted high marks. This was evident enough that something was wrong" This confession by informants is supported by Alutu and Aloyede (2006) who found that stakeholders seem to have knowledge about examination unprofessional conduct taking place in the classrooms daily and unethical issues. In line with this situation, Heyneman (2009) warned that corruption in any assessment in the education systems has long term cost effects and consequences which have long term bearing in the economy of a country hence the need to guard against it. For example, the author quote as follows, '. . . if we produce a foolish agriculturist, and he chooses a bad crop, a bad seed, the results will affect all of us. . .'p.10. Thus, the decision to have one agriculture project was to uplift the quality of assessment in agriculture.

Professional development: some participants echoed the view that there was need for appropriate advanced education for teachers in schools so that they will be able to consider examinations a crucial component of their professional activities. They stated that "teachers of agriculture were not properly trained/prepared to handle examinations. So we are all not sure of what is important in teaching - passing students or uplifting the profession of teaching". This is suggesting that teachers of agriculture need to be trained for personal and professional development to understand the importance of assessment. The participant further stated that "If we want the teaching of agriculture to be a "profession" we should also be professional in our teaching". The quotes also have implication of attitudes which need to be changed, may be through training.

Diversity in agricultural education: several teachers echoed the fact that teachers of agriculture were expected to perform a variety of activities even at odd hours when other teachers had finished work for the day. The conditions of work and payment scales, promotions to positions of responsibility were limited for agricultural teachers. Currently, agriculture is treated like a practical subject not a science subject and teachers are not considered for scare skills (the government of Botswana has identified areas where there is shortage of personnel and incentivised them with a $40 \%$ of their salary as an attraction and retention strategy). The impression is that agriculture should be taught and treated as a science and practical subject which also attract scare skills like other sciences. Noted also in terms of diversity is that teachers were prepared to graduate with agricultural education, diploma in secondary education, diploma in animal science. These variations and diversities found in the teaching of agriculture in schools also impact results in schools.

Project Monitoring: there seem to be limited checks provided by the Ministry of Education and Skills Development (MoESD) that are considered in teaching of the subject. Participants indicated that there were no standards to base the 
work of a teacher on practical subjects particularly agriculture. School inspectorate directorate should have agriculture orientation in order to monitor the school projects, the processes and not only the product. Resources and infrastructure for teaching of agriculture in schools were some of the issues raised by participants as a concern in teaching agriculture. Teacher \# 1 suggested that if all projects in schools were to be considered in the final examinations there would be need to have laboratories for the teaching of the subject. The majority of the respondents agreed that resources for agriculture need to be re-considered to improve the practicality of the subject in schools.

\section{Discussions and Conclusions}

It is clear that this research has not exhausted all that needs to be known about the teaching of Agriculture in Botswana schools. So the results are not applicable to the whole country, but the study has not established that through this research. It is however important to note that the research does give an indication of what is out there in the field.

Based on the information gathered, teachers of agriculture in secondary schools in Botswana were given the mandate to identify specific skills to be learnt by students. Although this empowers teachers in their job, the results imply that students in different schools were likely to be assessed on different skills and were likely to show variations in the mark allocations, skills assessed and proficiency acquired by learners. The performance of students from one school to the other was likely to vary depending on project availability.

The results also confirm that standards in education were important as they provide guidance on the outcomes of any expected learning outcome. The provision of teaching standards would enable the system to avoid what has been described by Teacher \# 1 who argued: "gone are the days when teaching was taken by all as a career of choice, today teachers of agriculture are no longer taking agriculture with passion hence some do not fear to hike marks for students." This hiking of marks would not happen if there was a standard set objectives which every student of the programme would have to satisfy.

Teacher 1 (Mr. John) also gives the impression that "wrong people" are teaching agriculture. If people take teaching because they want something else and couldn't care what happens to students' learning, it means the profession needs to have standards in recruiting, training and monitoring the teaching process.

The participants stated that resources were inadequate for agricultural science projects thus contributing to limitations on what to assess during examinations. Inadequate teaching resources are a critical component of education. It is therefore instructive that authorities in education are not responsive to the needs of educational institutions and the examination authority is not demanding quality which would force changes towards the provision of facilities.

The participants believed that supervising students in conducting practical projects was an additional function to their classroom teaching. These negative perceptions about practical projects in schools have been noted and have implications on the roles and functions of a teacher. Perhaps it is time higher education programs set teaching standards to guide preparations of agriculture teachers. Similarly, it is time for the MoESD to consider teacher certification for selection of teachers. As indicated by the Teacher Licensure (Certification) Research Brief (n.d), teacher certification is a system used in the USA to control individuals who are allowed to teach in schools. The system places emphasis on individuals holding appropriate Bachelor's degree, having spent a considerable period in pursuing relevant courses [programme] and are able to think and solve problems. Good teachers are good thinkers and problem solvers' (David Roth and Watson Scott Swail, 2000)

As indicated by Ibukun and Oyewole (2011) authorities responsible for examinations take the lead in protecting their integrity as the organisation responsible for examinations. Malpractices in education come in many forms and may hamper the education system. The University of Cambridge Local Examinations Syndicate (UCLES for example has run the examinations for many countries ensuring the standards were kept at a level where examinations serve the purpose they were designed to serve. Similarly it was not shocking as stated by the participants that the Botswana Examinations Council (BEC) saw a need to suspend some practical components of agriculture because of lack of standards guiding school-based practical assessment as a whole and a reliability of scores given to students for practical. It is notable though that the reduction of practical examination components for agriculture has not necessarily led to a comprehensive assessment of the subject so that the examinations would be high quality.

Based on the study, several issues were emerged such as teacher motivation to perform the expected work at odd hours or after normal school hours. There is little monitoring of the activities carried out in schools by students to ensure that marks awarded to students were indeed their own. Students should carry out the projects under the supervision of the teacher and also verified by the moderator. This has implications for the validity of the scores and projects allegedly conducted by students. The Ministry of Education and Skills development (MoESD) together with other stakeholders need to set teaching standards, assessment standards, and monitoring standards and further certify teachers who teach and handle student marks. 
The study therefore concludes by forming basis for understanding the culture and practices of teaching and assessing practical agriculture projects in Botswana schools to be guided by (1) teacher motivation (2) validity issues on assessment (3) teaching standards, (4) teacher education, and (5) practices in teaching. The study found that participants noted several thematic areas as factors contributing to scaling down of practical components in assessment. A more comprehensive study is recommended.

\section{References}

Alam, G. M., Hoque, K. E., Taher, B. K., T. B., Siraj, S. B., \& Ghani, M. F. B. A. (2009). The role of agriculture education and training on agriculture economics and national development of Bangladesh. African Journal of Agriculture Research, 4(12), 1334-1350.

Alutu, A. N. G., \& Aluede, O. (2006). Secondary Schools Student's Perception of Examination: Malpractices and Examination Ethics. Journal of Human Ecology, 20(4), 295-300.

Anderson, R. (2007). Thematic Content Analysis (TCA) 1 Descriptive Presentation of Qualitative Data. Available at file:///C:/Users/khulela/Desktop/ThematicContentAnalysis.pdf

Bulus, I., \& Rimfat, D. Z. (2001). Promoting examination ethics: implications for Nigerian teachers.

Chan, R. (2004). Continuous Assessment for Evaluating and Guiding Student Learning [Ppt] Online.

Conroy, C. A., \&. Walker, N. J. (2000). An examination of integration of academic and vocational subject matter in the aquaculture classroom. Journal of Agricultural Education, 41(2). https://doi.org/10.5032/jae.2000.02054

Dorrnody, T. (1993). Science credentialing and science credit in secondary agricultural education. Journal of Agricultural Education, 34(2), 63-70. https://doi.org/10.5032/jae.1993.02063

Egun, A. C. (2009). Focusing Agricultural Education for Better Productivity in Nigeria in the $21^{\text {st }}$ Century." International Journal of Education Science, 1(2), 87-90.

Hare, C., \& Waterston, K. (2003). Supporting Institutional Records Management. Theme 1a Managing Student Assessment Records. Northumbria University. Information management Research institute. http://www.jisc.ac.uk/media/documents/programmes/supportingirm/studentassessmentrecordsfinalreport.pdf

Heyneman, S. P. (2009). Introduction: the importance of external examinations in education, in Vlaardingngerbroek, B. and Taylor N. (2009) (edits) Secondary school external examination systems.

Heyneman, S. P., \& Fremer, J. (June 2008). The Importance of Fair Education Selection', Report for the World Bank.

Hsieh, H. F., \& Shannon, S. E. (2005). Qualitative Health Research: Three Approaches to Qualitative Content Analysis. Published by Sage: http://www.sagepublications.com

Ibara, E. C. (April 2008). Administering examinations for quality control in distance education: the National Open University of Nigeria perspective. Turkish Online Journal of Distance Education-TOJDE, 9(1), 1302-6488.

Ibukun, W. O., \& Oyewole, B. K. (2011). Examination malpractices in Nigerian schools: Environmental influences and management strategies. International Journal of Business and Management Tomorrow, 1(2).

Knobloch, N. A., Ball, A. L., \& Crystal, A. C. (2007). The benefits of teaching and learning about agriculture in elementary and junior high schools, Journal of Agricultural Education, 48(3)3, 25-36. https://doi.org/10.5032/jae.2007.03025

Mistica, M., Baldwin, T., Cordella, M., \& Musgrave, S. (2008). Applying discourse analysis and data mining methods to spoken OSCE assessments. Proceedings of the $22^{\text {nd }}$ International Conference on Computational Linguistics (pp. 557-584). Manchester. August. https://doi.org/10.3115/1599081.1599154

Myers, B. E., \& Dyers, J. E (2004). Agriculture teacher education programs: a synthesis of the Literature. Journal of agricultural Education, 45(3), 44-52. https://doi.org/10.5032/jae.2004.03044

Nurul, S. M. Y., Maimunah, S., \& Mohd, S. A. R (2011). Measuring Performance for Classroom Facilities. 2011 International Conference on Sociality and Economics Development IPEDR vol.10 (2011) @ (2011) IACSIT Press, Singapore

Oche, E. S. (2012). Assessing the Impact of Examination Malpractices on the Measurement of Ability in Nigeria, International J. Soc. Sci. \& Education, 2(4), ISSN: 2223-4934 E and 2227-393X Print

Osborne, E. D. (1983). Teaching Strategies for Developing Psychomotor Skills. NACTA Journal, - March 1986

Reeves, S., Kuper, A., \& Hodges, B. D. (2008). Qualitative Research Qualitative research methodologies: ethnography

Retallick, M. S. (2010). Implementation of Supervised Agricultural Experience Programs: The agriculture teachers' 
perspective. Journal of Agricultural Education, 51(4), 59-70. https://doi.org/10.5032/jae.2010.04059

Roth, D., \& Swail, W. S. (2000). Certification and teacher preparation in the United States. Educational Policy Institute Washington, DC: Improving educational policy \& practice through research. http://www.educationalpolicy.org/pdf/prel\%20certification.pdf

Shenton, A. K. (2004). Strategies for ensuring trustworthiness in qualitative research projects Education for Information 22(2004), 63-75 63. IOS Press. 0167-8329/04/\$17.002004-IOS Press and the authors.

Syakima, N., Sapri, M., \& Shahril, A. R. (2011) Measuring performance for classroom facilities. Paper presented at the 2011 International Conference on Sociality and Economics Development, Kuala Lumpur, 4-5 June.

Talja (n.d). Analyzing Qualitative Interview Data: The Discourse Analytic Method. University of Tampere, Finland. Available online at http://people.uta.fi/ lisaka/LISR\%5b1\%5d.pdf

Teacher Licensure Brief (n.d) Centre for Urban and multicultural education: Teacher licensure brief. Indiana University School of Education. http://education.iupui.edu/ CUME/pdf/Teacher\%20Licensure\%20Brief.pdf

The Family Health International (n.d) Qualitative Research Methods: A Data Collector's Field Guide Module 1 Qualitative Research Methods Overview. http://www.ccs.neu.edu/course/is4800sp 12/resources/qualmethods.pdf

\section{Copyrights}

Copyright for this article is retained by the author(s), with first publication rights granted to the journal.

This is an open-access article distributed under the terms and conditions of the Creative Commons Attribution license which permits unrestricted use, distribution, and reproduction in any medium, provided the original work is properly cited. 